\title{
Household structure and living arrangements among older persons in selected West Africa Countries: evidence from demographic and health surveys
}

\author{
Jacob Wale Mobolaji ${ }^{1}$, Friday Asiazobor Eboiyehi ${ }^{2}$, \& \\ Akanni Ibukun Akinyemi ${ }^{1}$ \\ ${ }^{1}$ Department of Demography and Social Statistics, Obafemi Awolowo University, \\ Ile-Ife, Nigeria \\ ${ }^{2}$ Centre for Gender and Social Policy Studies, Obafemi Awolowo University, \\ Ile-Ife, Nigeria \\ E-mail: mobolawale@gmail.com
}

\begin{abstract}
Background: Older persons' living arrangements are currently major development discourses across Africa. With the increasing family nucleation, weakening traditional ties and support networks, what is the emerging pattern of living arrangements of the older persons within this changing social system in West Africa?

Methods: The study utilized DHS household data on older persons aged 60 years and above in selected West African countries: Benin Republic, Cote d'lvoire, Ghana, Niger, Nigeria, Senegal and Togo $(n=31,695)$.

Results: Results showed that West African older persons had an average of 5.0 household network members; proportion living alone were higher among women $(21.6 \%)$ than men (10.4\%), majorly widows (31.3\%) or single/divorced (38.0\%). Household network, headship and living arrangements varied significantly across countries by age, sex, education, marital status and wealth quintile $(p<0.05)$.

Conclusion: The study concludes that the emerging pattern of older persons living alone is relatively high, suggesting age-friendly re-assessment of the traditional support system and household resources allocation.
\end{abstract}

Keywords: Living arrangements, household structure, elderly, older person, West Africa, support network

\section{Introduction}

Globally, the population of older persons is increasing with about 8 million per year since year 2000; and by 2030, this increase will reach 24 million. Evidence also suggest that the proportion of people aged over 60 years is growing faster than any other age groups, and about 2 billion people will be aged 60 and older by 2050 (United Nations, 2015). The increase is expected to be remarkable in the developing countries of Asia, Latin America and sub-Saharan Africa with estimates suggesting an increase from 375 million in 2000 to 1.6 billion in 2050 (Aurora, 2015; United Nations, 2015). According to these projections, the proportion of those 75 years and over will increase by $526 \%$ in Western Africa. Accordingly, West Africa will have the largest population of older persons 75 years and above within Africa and the seventh in the world (United Nations, 2015). This will have implications for social structures and facilities. Among these are issues related to the challenges such will pose on socioeconomics and living standards, health systems, and living arrangements for the older persons and their households. The current discourse is central on the living arrangements of the older person and the emerging issues in West Africa.

Whereas African traditional system emphasizes extended family system and consanguinity as a veritable living arrangement for older person (Akiwowo, 1978; Apt, 2000; Akinyemi, 2009), such arrangement is fast eroding (Togonu-bickersteth \& Akinyemi, 20l4). The traditional family structure is witnessing some form of detachment of children from their older parents due to growing emphasis on individualism and romantic love as the basis for marriage. This is further worsened by the current economic downturn that tends to create for 
individuals a direction of independence from the larger family (Togonu-Bickersteth, 1997). In the process, extended kinship ties are weakening and the nuclear family becomes an independent unit and appendage of extended family setting.

The traditional Africa system is such that the older persons are taken care of as a filial responsibility of the family. The common living arrangements of the older persons is to live in households with relations. These households in most cases present different typologies of compositions with varying forms of dependency. Other relations likely to be found in the household of older persons are sisters and brothers, nieces and nephews and, occasionally, cousins (Apt, 1996). Such residential arrangement has the potentials to facilitate efficient reinforcement of social, emotional and psychological support, and resources sharing for mutual well-being of network members. Besides, quality social interactions predispose physical health (Barger, 2013; Berkman \& Glass, 2000; Cohen, 2004; Holt-Lunstad, Smith \& Layton, 2010) and closely associate with low mortality or risk thereof (Cerhan \& Wallace, 1997; Holt-Lunstad et al., 2010). A good social support eases out effect of stress in older persons (Cohen, 2004; Holt-Lunstad et al., 2010).

However, social changes and modernization have impacted such traditional arrangements. With the growing population of this group of people across West Africa, and the changing traditional values and systems, there is the need for a paradigm shift in planning for the future that will be responsive to the challenges occasioned by this demographic shift. Although most countries in the western world overcome this through a well-established formal home care and residential arrangements, such arrangements are foreign to Africa continent particularly West Africa (Akinyemi, Ibinaiye, \& Togonu-Bickersteth, 20I6).

Evidence, however suggests that most West African countries in the foreseeable future, is unlikely to have at its disposal sufficient resources to build a comprehensive welfare state to meet the needs of its newly enfranchised poor. Thus, concerns about household structure and support for older persons are becoming increasingly important in contemporary African society. In the face of the changing social structures and resources constraints, what are the emerging patterns of living arrangements of older persons that have implications on their well-being? What factors predispose the living arrangements? These are some of the questions that trigger this study. They require timely attention in order to address the issues of current challenges and forestall future "catastrophic spending" on this growing older people's population. The empirical evidence from this study will serve as a guide for program and policy actions on improving wellbeing of older persons in West African sub-region.

\section{Methods}

\section{Data sources}

In this study, secondary data from the most recent Demographic and Health Surveys (DHS) in West African countries were extracted and analyzed to achieve the objectives of the study; the DHS used with their years of data collection include household survey dataset of Benin Republic (20I I/20I2), Niger (20I2), Cote d'lvoire (20II/20I2), Senegal (20I4), Ghana (20I4), Nigeria (20I3) and Togo (20I3/20I4).

\section{Sampling procedures}

The DHSs household survey datasets are nationally representative data eliciting demographic and health information about individuals in sampled households on cluster basis across the country. The clusters regarded as primary sampling unit were based on the enumeration areas used for the most recent population and housing census of each country. A stratified two-stage cluster sampling design was used to arrive at the households interviewed in the surveys. The details of sample design and data collection methods for each country were published elsewhere (Direction Générale de la Statistique DGS/Gabon \& ICF International, 20I3; Ghana Statistical Service-GSS, Ghana Health Service-GHS, \& ICF International, 20I5; Institut National de la Statistique - INS/Cameroun \& ORC Macro, 20I2; Institut National de la Statistique - INS/Côte d'lvoire \& ICF International, 20I2; Institut National de la Statistique et de l'Analyse Économique-INSAE/Bénin \& ICF International, 20I3; Ministère de la Planification, du Développement et de l'Aménagement du Territoire - MPDAT/Togo, Ministère de la Santé - MS/Togo, \& ICF International, 2015; National Population Commission NPC/Nigeria \& ICF International, 20I4; (ANSD/Sénégal \& International, 20I5; INS/Niger \& International, 2013). This study focused on the older members of the household aged 60 years and above; hence, of the household members interviewed, data relating to individual socio-demographic characteristics, household size and relationship structure were extracted from the datasets for all eligible respondents. A weighted total sample of 3I,695 sample extracted from the datasets of Benin Republic $(n=4,948)$, Niger $(n=3,440)$, Cote d'lvoire $(n=2,754)$, Senegal $(n=2,305)$, Ghana $(n=3,157)$, Nigeria $(n=10,883)$ and Togo $(n=2,862)$ were used. 


\section{Variables and measurements}

The dependent variables for this study are the household size, living arrangements and household headship. The household size is a single variable with count numeric data in the dataset captured as number of household members; living arrangements was captured as relationship structure. Respondents who reported relationship structure as one adult were categorized as living alone while other responses were categorized otherwise. Also, household headship was generated from the "relationship to head" in the dataset; all respondents who reported "head" were categorized as household heads while all other respondents were nonhousehold heads. However, all missing values and "don't know" responses were excluded from the analysis. The independent variables are the sociodemographic characteristics of the respondents including age, sex, education, marital status, place of residence and wealth quintile as reported in the dataset.

\section{Statistical analyses}

The data for this study was analyzed at univariate, bivariate and multivariate levels using Stata software (version 13.0). The background characteristics and household arrangements of the respondents in each selected country in West Africa were depicted in percentage distributions. Poisson regression was used to determine the association between each of the background characteristics and size of the household in which they live using unadjusted incidence rate ratio (IRR) result; adjusted IRR was used to determine the multivariate differentials of household size of the study sample. Poisson regression is appropriate when the outcome variable, such as household size in this study, is numeric and contains count data. Since household size matches this criterion, Poisson regression was the most appropriate. Also, binary logistic regression was used to examine associations between background characteristics and each of living arrangements and household headship among older adults in West African countries using unadjusted odds ratio (OR); in this case also, adjusted OR was used to determine the differentials of living arrangements and household headship among older persons in West African sub-region at multivariate level. Their relationship to household heads was also described using percentages. All analyses were based on $95 \%$ confidence interval.

\section{Results}

The result in Table I revealed that across the selected countries in West African sub-region, more than half of the respondents were in their early old age, 60-69 years of age in Benin Republic (56\%), Niger (59\%), Cote d'lvoire (62\%), Senegal (59\%), Ghana (56\%), Nigeria (57\%) and Togo (57\%); less than $10 \%$ of the respondents were in the oldest age group (85 years and above). The distribution is indicative of low life expectancy in the sub-region.

Slightly higher than half of the proportion of older persons were females in Togo (55\%), Ghana (55\%) and Senegal (5l\%), compared with Benin, Niger, Cote d'lvoire and Nigeria with lower proportion of female older persons in the households. More than two-thirds of older persons in West Africa had no formal education; mostly in Niger (97\%), Senegal (89\%), Cote d'lvoire (84\%), Benin Republic (82\%) and Togo (72\%). As further shown, though more than $60 \%$ were currently married, about one-third of older persons in West Africa were widowed. Widowhood was more prevalent in Togo (39\%) and Ghana (34\%) compared to other countries under study. However, majority of the widows were women (result not shown). About two-fifths of older persons $(40 \%)$ were in the lower wealth quintile (poorest or poorer), except Nigeria (39\%) while about $25-35 \%$ were richer or richest. Except in Gabon, Ghana and Nigeria, nearly more than twothirds majority of the older people live in rural areas in Niger (85\%), Togo (72\%), Cote d'lvoire (65\%) and Benin Republic (64\%).

Table I: Percentage distribution of Socio-demographic characteristics of older persons in West Africa

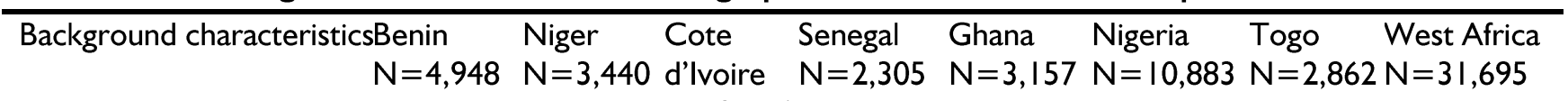
$N=2,754$

\begin{tabular}{lcccccccc}
\hline Age group (in years) & & & & & & & & \\
$60-64$ & 33.2 & 39.7 & 39.0 & 35.0 & 33.9 & 34.7 & 34.6 & 35.3 \\
$65-69$ & 22.8 & 19.7 & 23.3 & 23.5 & 21.7 & 22.0 & 22.5 & 22.1 \\
$70-74$ & 18.2 & 22.0 & 18.7 & 17.5 & 17.5 & 19.3 & 18.2 & 18.9 \\
$75-79$ & 9.8 & 7.4 & 8.3 & 11.7 & 11.8 & 9.5 & 9.2 & 9.6 \\
$80-84$ & 8.9 & 6.6 & 5.8 & 7.1 & 6.8 & 8.2 & 7.4 & 7.6 \\
$85+$ & 7.1 & 4.6 & 4.9 & 5.2 & 8.4 & 6.3 & 8.2 & 6.4 \\
Sex & & & & & & & & \\
Male & 51.6 & 61.8 & 53.5 & 49.0 & 44.7 & 54.8 & 44.6 & 52.5 \\
http://aps.journals.ac.za & & & & & & & &
\end{tabular}




\begin{tabular}{|c|c|c|c|c|c|c|c|c|}
\hline Female & 48.4 & 38.2 & 46.5 & 51.0 & 55.3 & 45.2 & 55.4 & 47.5 \\
\hline \multicolumn{9}{|c|}{ Highest Educational level } \\
\hline No formal education & 82.1 & 97.1 & 84.2 & 89.2 & 53.4 & 68.9 & 71.9 & 75.9 \\
\hline Primary & II.I & 1.6 & 8.5 & 5.4 & 9.6 & 19.6 & 18.5 & 12.9 \\
\hline Secondary & 4.9 & 0.9 & 6.2 & 3.2 & 31.2 & 6.9 & 7.4 & 8.2 \\
\hline Tertiary & 1.9 & 0.4 & I.I & 2.2 & 6.0 & 4.5 & 2.2 & 3.1 \\
\hline \multicolumn{9}{|l|}{ Current marital status } \\
\hline Never married & 1.1 & 0.4 & 1.3 & 1.1 & 0.8 & 0.6 & 0.7 & 0.8 \\
\hline Married & 62.8 & 76.6 & 61.9 & 65.2 & 52.7 & 68.9 & 55.5 & 64.9 \\
\hline Widowed & 31.4 & 21.6 & 31.9 & 30.8 & 34.3 & 28.3 & 39.1 & 30.2 \\
\hline Divorced & 4.6 & 1.4 & 4.9 & 2.9 & 12.1 & 2.2 & 4.6 & 4.1 \\
\hline \multicolumn{9}{|l|}{ Wealth quintile } \\
\hline Poorest & 25.8 & 25.2 & 26.1 & 22.4 & 21.5 & 17.8 & 18.9 & 21.1 \\
\hline Poorer & 21.6 & 22.9 & 26.4 & 22.4 & 25.2 & 20.8 & 23.3 & 22.6 \\
\hline Middle & 20.8 & 18.4 & 20.1 & 19.6 & 21.9 & 26.0 & 17.6 & 23.5 \\
\hline Richer & 16.6 & 17.2 & 15.3 & 16.7 & 16.2 & 20.7 & 16.9 & 17.9 \\
\hline Richest & 15.2 & 16.3 & 12.1 & 18.8 & 15.3 & 14.7 & 13.2 & 15.0 \\
\hline \multicolumn{9}{|l|}{ Residence } \\
\hline Urban & 36.0 & 14.7 & 35.0 & 42.7 & 48.0 & 40.6 & 28.0 & 36.2 \\
\hline Rural & 64.0 & 85.3 & 65.0 & 57.3 & 52.0 & 59.4 & 72.0 & 63.8 \\
\hline
\end{tabular}

Differentials of living alone among older persons in West Africa

In Table 2, the proportion and probability of living alone varied significantly across West African countries $(p<0.05)$. As indicated by the unadjusted odds ratio of binary logistic regression (model I), older adults in Ghana and Benin had $57 \%$ and 18\% respectively higher odds of living alone while those in Togo, Cote d'lvoire, Niger and Senegal had 16 $90 \%$ lower odds of living alone compared to their counterparts in Nigeria (reference category). Adjusting for other factors in model 2, the odds of living alone got lower for older persons in Ghana (13\%) and Benin (40\%) but was consistent in other countries in the study except Senegal.

Furthermore, living alone was significantly associated with age, sex, level of education, marital status and wealth quintile of respondents $(p<0.05)$. Older persons who were of older age were more likely to live alone relative to those in the youngest age group. Having adjusted for other factors, the association faded in the older age groups. Though, women had more than two-fold higher odds of living alone compared to men as revealed by the unadjusted odds ratio in model I, when adjusted for other factors, they were by $10 \%$ less likely to live alone than men. Similarly, widowhood and being single or divorced were significantly associated with living alone; with reference to the married, the odds of living alone was about eight-fold higher for widows (unadjusted $\mathrm{OR}=7.83, \mathrm{p}<0.05 ; 95 \%$ C.I. $=7.5 \mathrm{I}$ 8.78) and much more for singles or divorced (unadjusted $\mathrm{OR}=10.59, \mathrm{p}<0.05 ; 95 \% \mathrm{C} . \mathrm{I} .=\mathrm{I} \mathrm{I} .40-$ 14.62). Older persons who were rural dwellers had $13 \%$ lower odds of living alone compared to urban counterparts; the result was consistent when adjusted for other factors.

Considering the socioeconomic factors, the unadjusted result indicated that primary education was associated with $24 \%$ higher odds of living alone, compared with those with no formal education. However, with the adjusted result, primary and secondary/higher education resulted in $51 \%$ and $88 \%$ higher odds of living alone respectively. Also, compared to the poorest, the odds of living alone was higher for poorer, middle/richer older people by $49-96 \%$ but $21 \%$ lower for those in the richest category. However, richer wealth quintile lost statistical significance when adjusted for other factors. 
Table 2: Percentage of older persons living alone and logistic regression results of differentials of living alone among older adults in Western Africa

\begin{tabular}{|c|c|c|c|c|}
\hline Background Characteristics & $\begin{array}{l}\% \\
\text { living } \\
\text { alone }\end{array}$ & $\begin{array}{c}\text { Number of } \\
\text { Older } \\
\text { persons }\end{array}$ & $\begin{array}{l}\text { Model I } \\
\text { Unadjusted OR } \\
\text { (95\% C.I.) }\end{array}$ & $\begin{array}{l}\text { Model } 2 \\
\text { Adjusted OR } \\
\text { (95\% C.I.) }\end{array}$ \\
\hline \multicolumn{5}{|l|}{ Country } \\
\hline Nigeria & 17.7 & 10,883 & 1.00 & 1.00 \\
\hline Benin & 15.3 & 4,948 & $1.18(1.08-1.29)^{* * * *}$ & $0.60(0.52-0.7 \mathrm{I})^{* * * * *}$ \\
\hline Niger & 8.0 & 3,440 & $0.48(0.42-0.55)^{* * *}$ & $0.4 \mathrm{I}(0.36-0.48)$ **** \\
\hline Cote d'Ivoire & 10.0 & 2,754 & $0.61(0.53-0.69)$ **** & $0.08(0.06-0.10)$ **** \\
\hline Senegal & 2.6 & 2,305 & $0.10(0.08-0.14) * * * *$ & $0.91(0.80-1.03)$ \\
\hline Ghana & 24.6 & 3,157 & $1.57(1.43-1.72)$ **** & $0.87(0.79-0.97)^{* * *}$ \\
\hline Togo & 15.1 & 2,862 & $0.84(0.74-0.94)$ ** & $0.54(0.47-0.62)$ *** \\
\hline \multicolumn{5}{|l|}{ Age group (in years) } \\
\hline $60-64$ & 11.9 & 10,725 & 1.00 & 1.00 \\
\hline $65-69$ & 14.5 & 6,708 & 1.28 (I.I7-I.40) ***** & $\mathrm{I} .1 \mathrm{I}(\mathrm{I} .00-\mathrm{I} .22) *$ \\
\hline $70-74$ & 15.0 & 5,751 & $1.37(1.25-1.50) * * *$ & $1.08(0.97-1.20)$ \\
\hline $75-79$ & 18.0 & 2,909 & $1.58(1.42-1.77) * * *$ & $1.15(1.01-1.30) *$ \\
\hline $80-84$ & 17.0 & 2,313 & $1.58(1.40-1.78) * * *$ & $1.04(0.90-1.19)$ \\
\hline $85+$ & 17.2 & $\mathrm{I}, 944$ & $1.62(1.43-1.84) * * *$ & $0.91(0.79-1.05)$ \\
\hline \multicolumn{5}{|l|}{ Sex } \\
\hline Male & 9.0 & 15,936 & 1.00 & 1.00 \\
\hline Female & 20.3 & $14,4 \mid 2$ & $2.66(2.49-2.84) * * *$ & $0.90(0.82-0.99) *$ \\
\hline \multicolumn{5}{|l|}{ Highest Educational level } \\
\hline No formal education & 14.0 & 22,672 & 1.00 & 1.00 \\
\hline Primary & 17.0 & 3,849 & $1.24(1.13-1.35)^{* * * *}$ & I.5। (I.36-I.69) **** \\
\hline Secondary/higher & 14.9 & 3,356 & $1.07(0.96-1.19)$ & $1.88(1.64-2.16) * * *$ \\
\hline \multicolumn{5}{|l|}{ Current marital status } \\
\hline Married & 4.9 & $|9,44|$ & 1.00 & 1.00 \\
\hline Widowed & 30.4 & 9,050 & $8.12(7.51-8.78)^{* * * *}$ & $9.90(8.96-10.95)^{* * *}$ \\
\hline Others (single/divorced) & 40.5 & $|, 46|$ & $|2.9|(|1.40-| 4.62)^{* * * *}$ & $13.56(|1.85-| 5.5 \mid)^{* * * *}$ \\
\hline \multicolumn{5}{|l|}{ Wealth quintile } \\
\hline Poorest & 11.0 & 6,397 & 1.00 & 1.00 \\
\hline Poorer & 15.7 & 6,846 & $1.60(1.45-1.76)^{* * * *}$ & $1.36(1.22-1.52)^{* * * *}$ \\
\hline Middle & 18.5 & 7,123 & $1.96(1.78-2.15) * * * *$ & $1.43(1.28-1.59)^{* * * *}$ \\
\hline Richer & 15.6 & 5,444 & $1.49(1.34-1.66)^{* * * *}$ & $0.98(0.86-1.12)$ \\
\hline Richest & 9.1 & 4,539 & $0.79(0.69-0.90)$ *** & $0.42(0.36-0.50) * * *$ \\
\hline \multicolumn{5}{|l|}{ Residence } \\
\hline Urban & 15.5 & 10,976 & 1.00 & 1.00 \\
\hline Rural & 13.7 & 19,373 & $0.87(0.8 \mathrm{I}-0.93) * * *$ & $0.83(0.76-0.91) * * * *$ \\
\hline
\end{tabular}

Note: reference outcome category is living alone; C.I. confidence interval; OR odds ratio; Model I: bivariate analysis; Model 2: multivariate analysis

*** $p<0.001$; ** $p<0.01$; $p<0.05$

Older people's household size and associated factors in West Africa

The result in Table 3 displays the household size of older adults in West Africa. The household size presents the network of people available around older persons to interact with. The average household size for West Africa was 6.0, indicating that the older adults in the sub-region had around him/her an average network of 5 persons to interact with. However, there were country variations. For instance, older persons in Ghana with average household size of 4.2, Nigeria (4.9) and Benin (5.3) had less than the sub-region's average in their social networks, while their counterparts Niger, Cote d'lvoire and Senegal had more than the average. Those who were older olds, females, had 
secondary/higher education, widowed, single/divorced, living in urban areas, and were of middle or richer wealth quintile had smaller household sizes (ranges from 4.3 to 5.8) compared to their counterparts in other groups (ranges from 5.1 to 6.4 household members).

In the same Table, the result of Poisson regression analysis revealed that at bivariate and multivariate levels of analysis, there were statistically significant disparities in household size of older adults among countries in the sub-region $(p<0.05)$. Variations in the household size were associated with differences in age, sex, level of education, marital status, wealth quintile and place of residence $(p<0.05)$. The unadjusted incidence rate ratio (IRR) result (model I) showed that household sizes of older adults in Cote d'lvoire, Niger and Togo was by $21-61 \%$ higher, seven percent higher in Benin and about three-fold higher in Senegal compared with their counterparts in Nigeria; conversely, the household size was by

Table3:
14\% lower in Ghana. When adjusted for other factors (model 2), the results were consistent as indicated by the adjusted IRR.

The unadjusted IRR in model I further indicated that older adults who were of older age, females, higher education, widowed or single/divorced had significantly lower household size compared to their counterparts of other groups. The disparities were consistent after adjusting for other factors in the model. On the other hand, older adults in the poorer to the richest wealth quintiles had 4-9\% lower IRR of large household size compared to those in the poorest category. However, adjusting for other factors, the IRR of the household size was $6 \%$ and $17 \%$ more likely to be larger among older persons in the richer and richest wealth quintiles respectively. That of rural and urban residents also varied significantly, with higher IRR of large family size compared to the urban dwellers.

Table 3: Average household size and poisson regression results of incidence rate ratio of household size of older people in West Africa

\begin{tabular}{llll}
\hline \multirow{3}{*}{ Background characteristics } & Model I & Model 2 \\
\cline { 3 - 4 } & $\begin{array}{c}\text { Household size } \\
\text { Mean (SD) }\end{array}$ & $\begin{array}{l}\text { Unadjusted IRR } \\
(95 \% \text { C.I.) }\end{array}$ & $\begin{array}{l}\text { Adjusted IRR } \\
\text { (95\% C.I.) }\end{array}$ \\
\hline
\end{tabular}

West Africa

$6.0(4.8)$

Country
Nigeria

Benin

Niger

Cote d'lvoire

Senegal

Ghana

Togo
$4.9(3.5)$
$5.3(3.8)$
$6.4(4.0)$
$6.9(5.0)$
$12.9(7.7)$
$4.2(2.9)$
$6.0(4.1)$

1.00

$$
\begin{aligned}
& 1.07(\mathrm{I} .05-\mathrm{I} .08)^{* * * *} \\
& \mathrm{I} .30(\mathrm{I} .28-\mathrm{I} .32)^{* * * *} \\
& \mathrm{I} .40(\mathrm{I} .38-\mathrm{I} .43)^{* * * *} \\
& 2.6 \mathrm{I}(2.58-2.65)^{* * * *} \\
& 0.86(0.84-0.87)^{* * * *} \\
& \mathrm{I} .2 \mathrm{I}(\mathrm{I} .19-\mathrm{I} .23)^{* * * *}
\end{aligned}
$$

1.00

$1.08(1.06-1.09)^{* * * *}$

$1.23(1.21-1.25)^{* * * *}$

$1.43(1.40-1.45)^{* * * *}$

$2.60(2.56-2.64)^{* * * *}$

$0.93(0.92-0.95)^{* * * *}$

$1.25(1.23-1.27)^{* * * *}$

\section{Age group (in years)}

$\begin{array}{ll}60-64 \text { RC } & 6.3(4.7) \\ 65-69 & 5.9(4.7) \\ 70-74 & 5.9(4.7) \\ 75-79 & 5.8(4.9) \\ 80-84 & 5.8(4.9) \\ 85+ & 5.6(4.6)\end{array}$

\subsection{0}

$0.95(0.94-0.96)^{* * * *}$

$0.94(0.93-0.95)^{* * * *}$

$0.92(0.91-0.94)^{* * * *}$

$0.93(0.91-0.94)^{* * * *}$

$0.90(0.88-0.92)^{* * * *}$

$6.2(4.6)$

$5.8(4.9)$
1.00

$0.94(0.93-0.95)^{* * * *}$

1.00

$1.00(0.99-1.01)$
1.00

$0.96(0.95-0.97)^{* * * *}$

$0.96(0.95-0.98)^{* * * *}$

$0.94(0.93-0.96)^{* * * *}$

$0.98(0.96-0.99)^{* * *}$

$0.95(0.96-0.99)^{* *}$

Sex

Female

1.00

1.00

No formal education ${ }^{R C}$

Primary

$4.8(3.5)$

$0.82(0.80-0.83)^{* * * *}$

$0.89(0.88-0.91)^{* * * *}$

$0.76(0.75-0.77)^{* * * *}$

$0.82(0.80-0.83)^{* * * *}$

\section{Current marital status}

Married ${ }^{\mathrm{RC}}$

$6.4(4.8)$

1.00 
Widowed

Others (single/divorced)

$5.3(4.7)$

$4.3(4.1)$

Wealth quintile

$\begin{array}{ll}\text { Poorest } & \text { RC } \\ \text { Poorer } & 6.3(4.6) \\ \text { Middle } & 6.1(5.0) \\ \text { Richer } & 5.7(5.1) \\ \text { Richest } & 5.7(4.5) \\ & 6.1(4.3)\end{array}$
$0.82(0.82-0.83)^{* * * *}$

$0.66(0.64-0.68)^{* * * *}$
$0.8 \mathrm{I}(0.80-0.82) * * *$

$0.70(0.68-0.72)^{* * * *}$

\section{Residence}

Urban ${ }^{\text {RC }}$

$5.8(4.7) \quad 1.00$

1.00

1.00

Rural

$6.1(4.8)$

$1.06(1.05-1.07)$ *****

1.00

Note: reference outcome category is household size; C.I. - confidence interval; IRR incidence rate ratio; SD - standard deviation; Model I: bivariate analysis; Model 2: multivariate analysis

*** $\mathrm{p}<0.001 ;{ }^{* *} \mathrm{p}<0.01$; ${ }^{*} \mathrm{p}<0.05$

\section{Differentials of household headship status of older} people in West Africa

Status of household heads is very important in determining the living standard and economic situation of the household members, especially in African society characterized with intergenerational living arrangements. The assumptions that household head solely shoulders the responsibility of providing for economic well-being of the household calls for concern where older persons, who are economically dependant and are supposed to be provided for, assume the role of household heads. However, age, sex, education and wealth status of the household head might be important factors to consider in explaining the living condition of economically dependent older persons who are household heads.

Examining the gender difference, traditional African society is predominantly, male-headed households; however, the assumption that gender of household head influences disbursement of household resources and that society's economic resources are less accessed by female relative to male raise further concern about proportion of older women who are household heads. Besides, a poor household is indicative of the wealth status of the household head and the level of support derivable by members living in the household. Education as a known correlate of wealth status potentially and indirectly impacts the living condition of household members. The results of analysis in this study provided insight about the proportion and peculiarities of West African elderly people who are household heads.

In Table 4, the unadjusted odds ratio of binary logistic regression (model I) estimated the bivariate associations and variations in household headship of older persons by socioeconomic and sociodemographic characteristics. As indicated, proportion of household heads varied significantly among West African countries $(p<0.05)$. For instance, taking http://aps.journals.ac.za
Nigeria as the reference country for comparison, there was about $15-63 \%$ lower odds of being a household head among older adults in other countries, except Benin Republic and Niger where differences were not significant. The result was consistent having adjusted for other factors in model 2. These cross-country variations reflect some disparities in socioeconomic and socio-demographic situations of older persons in West African countries.

The result (model I) further revealed that proportion of household heads significantly varied by age, gender, education, wealth quintile and rural/urban residence $(p<0.05)$. However, the variations did not apply to all age groups, levels of education and wealth quintiles. Taking age group $60-$ 64 as the reference age, odds of being a household head was by $10-13 \%$ significantly higher in age groups $65-69$ and $70-79$ years but by $22 \%$ lower for the oldest olds. However, controlling for other factors in model 2, especially, country differences, older persons of 75 years and above were significantly less likely to be a household head. From gender perspective, West African women were by more than $99 \%$ less likely to be household heads irrespective of other factors, compared to men. This is similar to the effect of marital status; widows and single or divorced had $44 \%$ and $12 \%$ lower odds of being household heads respectively compared to the married. However, the interplay of marital status with other factors such as education and wealth quintile made them have more than threefold higher odds of being household heads. Also, rural dwellers had 19\% lower odds of being household heads; this was more pronounced when adjusted for other factors.

Considering the effect of socioeconomic factors, the odds of being a household head increased with the level of education, and wealth quintile. Those with primary and secondary or higher education had $4 \mathrm{I}-85 \%$ higher odds of being household heads respectively. The result remained within this range 4536 
when adjusted for other factors. Also, older persons who were in higher wealth quintile than the poorest were more likely to be household heads, as indicated in the unadjusted and adjusted results.

Table 4: Percentage of older persons who were household heads and logistic regression results of differentials of household headship among older adults in West Africa

\begin{tabular}{|c|c|c|c|c|}
\hline \multirow{2}{*}{ Background characteristics } & \multicolumn{2}{|c|}{$\%$ who are Number of } & \multirow{2}{*}{$\begin{array}{l}\text { Model I } \\
\mathrm{n}: \text { Unadjusted OR } \\
(95 \% \text { C.I.) }\end{array}$} & \multirow{2}{*}{$\begin{array}{l}\text { Model } 2 \\
\text { Adjusted OR } \\
(95 \% \text { C.I.) }\end{array}$} \\
\hline & household head & Older person: & & \\
\hline West Africa & 68.2 & 30,349 & & \\
\hline \multicolumn{5}{|l|}{ Country } \\
\hline Nigeria & 73.5 & 10,883 & 1.00 & 1.00 \\
\hline Benin & 71.2 & 4,948 & $0.94(0.88-1.01)$ & $0.98(0.89-1.08)$ \\
\hline Niger & 70.5 & 3,440 & $0.97(0.89-1.05)$ & $0.82(0.73-0.92)^{* *}$ \\
\hline Cote d'Ivoire & 65.5 & 2,754 & $0.70(0.64-0.76)^{* * * *}$ & $0.55(0.49-0.61)^{* * * *}$ \\
\hline Senegal & 51.4 & 2,305 & $0.37(0.34-0.40)^{* * * *}$ & $0.24(0.22-0.27)^{* * * * *}$ \\
\hline Ghana & 70.7 & 3,157 & $0.85(0.79-0.93)^{* * * *}$ & $0.85(0.76-0.94)^{* * *}$ \\
\hline Togo & 64.8 & 2,862 & $0.65(0.60-0.70)^{* * *}$ & $0.65(0.58-0.72)^{* * * *}$ \\
\hline \multicolumn{5}{|l|}{ Age group (in years) } \\
\hline $60-64$ & 68.2 & 10,725 & 1.00 & 1.00 \\
\hline $65-69$ & 71.0 & 6,708 & $1.13(1.06-1.20)^{* * *}$ & $1.00(0.92-1.09)$ \\
\hline $70-74$ & 70.6 & 5,751 & $1.11(1.04-1.19)^{* *}$ & $0.90(0.82-0.98)$ \\
\hline $75-79$ & 71.5 & 2,909 & $1.10(1.01-1.20)^{*}$ & $0.82(0.74-0.93)^{* *}$ \\
\hline $80-84$ & 68.8 & 2,313 & $0.97(0.89-1.07)$ & $0.67(0.60-0.75)^{* * * * *}$ \\
\hline $85+$ & 61.9 & 1,944 & $0.78(0.70-0.85)^{* * * *}$ & $0.44(0.39-0.50)^{* * * *}$ \\
\hline \multicolumn{5}{|l|}{ Sex } \\
\hline Male & 92.9 & 15,936 & 1.00 & 1.00 \\
\hline Female & 43.2 & $14,4 \mid 2$ & $0.06(0.05-0.06)^{* * * *}$ & $0.02(0.01-0.02)^{* * * *}$ \\
\hline \multicolumn{5}{|l|}{ Highest Educational level } \\
\hline No formal education & 65.4 & 22,672 & 1.00 & 1.00 \\
\hline Primary & 81.8 & 3,849 & $2.4 \mathrm{I}(2.22-2.62)^{* * * *}$ & I.57 $(1.4 \mathrm{I}-\mathrm{I} .75)^{* * * *}$ \\
\hline Secondary/higher & 83.4 & 3,356 & $2.85(2.59-3.13)^{* * *}$ & $1.58(|.37-| .8 \mid)^{* * * *}$ \\
\hline \multicolumn{5}{|l|}{ Current marital status } \\
\hline Married & 73.1 & $|9,44|$ & 1.00 & 1.00 \\
\hline Widowed & 61.7 & 9,050 & $0.56(0.53-0.59) * * * *$ & $4.99(4.6 \mathrm{I}-5.40)^{* * * * *}$ \\
\hline Others (single/divorced) & 71.9 & $\mathrm{I}, 46 \mathrm{I}$ & $0.88(0.78-0.99)^{*}$ & $3.19(2.74-3.71)^{* * * *}$ \\
\hline \multicolumn{5}{|l|}{ Wealth quintile } \\
\hline Poorest & 67.6 & 6,397 & 1.00 & 1.00 \\
\hline Poorer & 68.2 & 6,846 & $1.08(1.01-1.16)^{*}$ & $1.33(1.22-1.46)^{* * * *}$ \\
\hline Middle & 70.9 & 7,123 & $1.22(|.| 4-|.3|)^{* * * *}$ & $1.50(1.37-1.65)^{* * * *}$ \\
\hline Richer & 71.7 & 5,444 & $1.29(1.20-1.39)^{* * * *}$ & $1.20(1.08-1.34)^{* * *}$ \\
\hline Richest & 67.6 & 4,539 & $1.08(1.00-1.17)^{*}$ & $0.74(0.65-0.85)^{* * * *}$ \\
\hline \multicolumn{5}{|l|}{ Residence } \\
\hline Urban & 71.8 & 10,976 & 1.00 & 1.00 \\
\hline Rural & 67.9 & 19,373 & $0.8 \mathrm{I}(0.78-0.86) * * *$ & $0.66(0.6 \mathrm{I}-0.7 \mathrm{I})^{* * * *}$ \\
\hline
\end{tabular}

Note: reference outcome category is living alone; C.I., confidence interval; OR, odds ratio; Model I, bivariate analysis; Model 2, multivariate analysis

*** $\mathrm{p}<0.001 ;{ }^{* *} \mathrm{p}<0.01 ;{ }^{*} \mathrm{p}<0.05$

Relationship of older persons to household heads In Table 5, the result indicated the type of relationship older persons had with the household head by gender. As shown in the result, more than $90 \%$ of the men were household heads in the selected West African countries except in Senegal 
$(81 \%)$. In order, this was followed by the few proportion ( $3-7 \%$ ) across the sub-region who were fathers to the household head. Besides living with child, older adults in Senegal also lived with other relatives (4 percent), wife and siblings ( 3 percent each); whereas, proportions who were husband in Ghana (3 percent) and sibling in Cote d'Ivoire (3 percent) to the household head was next in the rank of the relationship structure.
Household headship was not common among women. Except in Ghana with more than half (54.4\%), about $32-47 \%$ of older women in other West African countries were household heads. Besides, about 17-37\% of the women were wives to the household heads while about 17-35\% were mothers to the household heads. On the average, the rest of the women were other relatives to household head (4 percent) or mother ( 3 percent) or sibling ( 3 percent) to the household head.

Table 5: Specific relationship to household head by gender and Country

\begin{tabular}{|c|c|c|c|c|c|c|c|c|}
\hline Household relationship & $\begin{array}{l}\text { Benin } \\
n=4,948\end{array}$ & $\begin{array}{c}\text { Niger } \\
n=3,440\end{array}$ & $\begin{array}{l}\text { Cote } \\
\text { d'lvoire } \\
n=2,754\end{array}$ & $\begin{array}{c}\text { Senegal } \\
n=2,305\end{array}$ & $\begin{array}{c}\text { Ghana } \\
n=4,586\end{array}$ & $\begin{array}{c}\text { Nigeria } \\
n=10,883\end{array}$ & $\begin{array}{c}\text { Togo } \\
n=2,862\end{array}$ & $\begin{array}{c}\text { Total } \\
\mathrm{N}=31695\end{array}$ \\
\hline \multicolumn{9}{|l|}{ Male } \\
\hline Household head & 94.1 & 94.5 & 91.5 & 80.6 & 90.8 & 95.4 & 90.9 & 92.6 \\
\hline Husband to hh & 1.4 & 0.2 & 0.9 & 3.1 & 3.1 & 0.6 & I.I & 1.2 \\
\hline Child/Adopted child to hh & 0.2 & 0.0 & 0.2 & 0.8 & 0.0 & 0.1 & 0.3 & 0.2 \\
\hline Spouse to child of hh & 0.0 & 0.1 & 0.0 & 0.3 & 0.0 & 0.0 & 0.0 & 0.0 \\
\hline Father to hh & 2.6 & 4.3 & 2.5 & 7.2 & 4.2 & 3.1 & 3.8 & 3.2 \\
\hline Father to spouse of hh & 0.2 & 0.3 & 0.1 & 0.7 & 0.6 & 0.2 & 0.5 & 0.3 \\
\hline Sibling to hh & 0.9 & 0.2 & 2.5 & 2.5 & 0.7 & 0.2 & 2.1 & 1.2 \\
\hline Other relative to hh & 0.5 & 0.5 & 1.8 & 4.1 & 0.5 & 0.3 & I.I & 1.1 \\
\hline Not related to hh & 0.1 & 0.0 & 0.6 & 0.8 & 0.0 & 0.1 & 0.2 & 0.3 \\
\hline \multicolumn{9}{|l|}{ Female } \\
\hline Household head & 46.8 & 31.8 & 35.7 & 23.4 & 54.4 & 47.0 & 43.7 & 45.3 \\
\hline Wife to hh & 28.6 & 37.5 & 24.8 & 16.6 & 19.5 & 28.9 & 23.3 & 24.9 \\
\hline Child/Adopted child to hh & 0.4 & 0.6 & 0.9 & 0.0 & 0.4 & 0.3 & 0.7 & 0.4 \\
\hline Spouse to child of hh & 0.0 & 0.2 & 0.1 & 0.2 & 0.0 & 0.1 & 0.0 & 0.1 \\
\hline Mother & 18.1 & 22.2 & 20.9 & 34.7 & 18.6 & 17.2 & 24.2 & 19.2 \\
\hline Mother to spouse of hh & 1.7 & 2.5 & 2.5 & 8.4 & 1.9 & 2.4 & 3.3 & 2.8 \\
\hline Sibling to hh & 2.1 & I.I & 5.6 & 3.8 & 1.7 & I.I & 2.3 & 2.6 \\
\hline Other relative to hh & 2.1 & 3.6 & 8.1 & 12.2 & 3.2 & 2.4 & 2.2 & 4.0 \\
\hline Not related & 0.3 & 0.7 & 1.5 & 0.7 & 0.3 & 0.6 & 0.3 & 0.7 \\
\hline
\end{tabular}

Note: hh - household head

\section{Discussion}

The continuity and survival of any society depends on its members' wellbeing, which is largely determined by the social cohesion, mutual support network and social welfare of the members. This paper examined the emerging pattern of living arrangement of older persons in West Africa with respect to living alone, household size, household headship and relationship to household head, and the predisposing factors. Each of the living arrangements variables implies older person's access to social interaction, social support network, household resources control and proximity to resources benefactor respectively.

In general, it is unusual in Africa to find older persons living alone. However, this is becoming a common phenomenon as the study indicated. Traditionally, older people live in households with relations comprising siblings, children and grandchildren. However, this intergenerational living arrangement is no longer the norm in West Africa. The results showed that a substantial proportion of 
older people are living alone in West Africa, except Senegal; and the likelihood of this is associated with older age, female gender, higher education, widowhood, single/divorced and higher wealth status. This outcome is linked to the detachment of extended family members from the aged due to the influence of modernization on family system (Togonu-Bickersteth, 1997). This is worsened by children's emigration from their aged parents for educational and economic reasons (Cruz \& Obiena, 199I; Okumagba, 20I I); resulting in children's nonavailability to care for their aged parents. This is largely caused by the shift from agrarian economy, through which family cohesion and stability was maintained, to mines and industries which put families at distance apart, thus weakening the traditional family ties (Apt, 2000). This pattern is strange to traditional African family setting characterized by well-articulated caring structure that allowed intergenerational intercourse and preserved the quality of life of older persons.

The picture which also emerged from the study indicated that a high proportion (20\%) of older women were living alone compared to men (9\%). This result is attributed to the fact that older men are more likely to be into polygynous marriages than their female counterparts. It implies that even when a man loses a wife, he may still co-reside with the other(s). It may also be attributed to lower life expectancy of men compared to women who are more likely to spend their old age alone in widowhood. The result suggests that older women who are widows, single or divorced are more vulnerable to neglect, isolation and loneliness which may have impact on their wellbeing. As the result indicated a higher proportion living alone among widows (30\%) and single/divorced (41\%), older men in these categories may be more vulnerable to neglect due to children's marginalization of fathers in caregiving (Noël-Miller, 2010).

From the result of this study, at least two-thirds of older persons were household heads except in Senegal. This proportion is generally high irrespective of age, education, marital status, residence and wealth quintile. However, it should be noted that most West African countries are low-income which indicate high level of poverty within the population. Based on this fact, household headship of widows $(62 \%)$, those in the poorest wealth quintile $(68 \%)$ and those with no formal education (65\%), may result in heavy household burden with health implications. This agrees with other findings (HelpAge International, 2008; Ogwumike \& Aboderin, 2005). However, in terms of household resources sharing, household heads have control over resources distribution. In West African patriarchal societies, women usually have less control over household resources.

As further found in this study, the lower proportion of household heads among women (43\%), compared to men (93\%), indicates a plausibility of their marginalization in household resources sharing, and this may limit their access to resources to improve their wellbeing. These findings are in tandem with other findings across many African countries (Bloom, Jimenez, \& Rosenberg, 201I; Omowumi, Taiwo, \& Olaotan, 2016; TogonuBickersteth, 1997). However, a wide country disparity is observed in female household headship. More than half is found in Ghana compared to other West African countries (see table 5). The high proportion in Ghana is linked to the fact that Ghana is a matrilineal society. However, more economic burden may be exacted on older women who assume the responsibility of maintaining household under dwindling economic environment of West African countries where there is no social welfare system for older persons (Eboiyehi, 20I3). This by implication could result in ill-health and mortality if not addressed.

Whom older people live with is important for security of their welfare. As observed in our study, older men who are neither household heads nor living alone largely live with their children (3\%) as the household head, while women either live with spouse (25\%) or children (19\%). An insignificant proportion co-reside with other relatives. The finding agrees with Aboderin (2004) and Akinyemi and Akinlo (2014) who stated that older people's support network which formerly included relatives has been shifted to children and spouse.

The study also found that household size presented a network of people that older people were interacting with. For instance, it indicated that though a proportion of older people are living alone, others had an average of 4.2 members within the household network to interact with to meet their need of social relationship. This finding can be attributed to the fact that Africans still value their older relatives; hence, some grandchildren whose parents are dead or not available still live with the aged grandparents. They provide support in social relationship and activities of daily living for older people. This agrees with the finding of Bongaarts and Zimmer (2002). However, though on one hand, household members provide emotional support to older persons through social interaction; on the other hand, they serve as economic burden, especially if they consist more of dependant children. Besides, the emotional support is possible only where there is quality social interaction among the household members (Kiecolt-Glaser \& Newton, 200I). 


\section{Conclusion}

Our study concludes that the current proportion of older persons living alone in West Africa is associated with male gender, 'lone' marital status (widowhood, single, separated, divorced), low level of education, poverty and urban residence, and this has implication on their wellbeing. Also, the decline in the size of household members that may constitute a network for emotional and physical support for older people occurs at older age, for those with higher level of education and in lone marital status. Finally, the study found that, a larger proportion of older people in West Africa are household heads and is associated with higher education, lone marital status and higher wealth status. However, the likelihood is low at older age, for women and rural dwellers for probable reasons of frailty or poverty at older age; women who are with husband as the household head; and some practice of intergenerational family system in the rural areas respectively. Meanwhile, it may result in marginalization in terms of resources sharing. These emerging patterns of household structure in West Africa have implications for older persons' wellbeing in the sub-region.

Our findings suggest the need for capitalization of social support network and programmes for older people who are at the verge of losing their right and relevance in the society. Economic empowerment and rural development are also recommended for adult children to be able to support their aged parents effectively. Finally, the study recommends that African cultural values of supporting older people should be integrated into its modernization process, transmitting the values through the educational systems.

\section{References}

Abdulraheem, J. P., \& Abdulrahman, A. C. (2008). Morbidity pattern among the elderly population in a Nigerian tertiary health care institution: analysis of a retrospective study. Nigeria Medical Practitioner, 54(2), 32-38.

Agence Nationale de la Statistique et de la Démographie - ANSD/Sénégal, and ICF International. 2015. Sénégal: Enquête Démographique et de Santé Continue (EDSContinue 2012-14), Rapport Régional. Rockville, Maryland, USA: ANSD/Sénégal and ICF International.

Akinyemi, I. A. (2009). Old age as a factor influencing high demand for children among the ljesa of South-Western Nigeria: Does number of children influence old age support? African Population Studies, 23(Suppliment), 6I-78.

Akinyemi, I. A., \& Akinlo, A. (20/4). Unmet Needs for Care and Support for the Elderly in Nigeria:
Gaps in Experiences and Expectations of the Aged in llesa, South-West Nigeria. The Nigeria Journal of Sociology Special Edition on Ageing in Nigeria, I2(I), 28-43.

Akinyemi, I. A., Ibinaiye, T., \& Togonu-Bickersteth, F. (2016). Africa, Aging and Families. The Wiley Blackwell Encyclopedia of Family Studies, I-4.

Akiwowo, A. (1978). Ajobi and Ajogbe: Variations on the Theme of Sociation. Inaugural Lecture Series 46. University of Ife, Nigeria

Anil, J. P., Joy, B., Malini, K., Kavita, V., Anita, V., \& Perushottam, P. (2006). Morbidity pattern among the elderly population in the rural area of Tamil Nadu, India. Turkey. Journal of Medical Sciences, 36, 45-50.

Apt, N. A. (1996). Coping with Old Age in a Changing Africa. Aldershot, United Kingdom: Avebury.

Apt, N. A. (2000). Rapid Urbanization and Living arrangements of Older persons in African Regon Centre for Social Policy Studies, University of Ghana.

Aurora, A. (20I5). Late-Life Living arrangements and Intergenerational Ties in Egypt: Elderly SocioEconomic Conditions from Labor Market Surveys. The Economic Research Forum (ERF) Giza Egypt.

Barger, S. D. (20I3). Social integration, social support and mortality in the US National Health Interview Survey. Psychosom Med, 75, 5I0-5I 7.

Berkman, L. F., \& Glass, T. (2000). Social integration, social networks, social support, and health. New York: Oxford University Press.

Bloom, D. E., Jimenez, E., \& Rosenberg, L. (20II) Social Protection of Older People. PGDA Working Paper.

Bongaarts, J., \& Zimmer, Z. (2002). Living arrangements of Older Adults in the Developing World: An Analysis of Demographic and Health Survey Household Surveys. The Journals of Gerontology Series B: Psychological Sciences and Social Sciences, 57(3), SI45-SI57. doi: 10.1093/geronb/57.3.SI45

Cerhan, J. R., \& Wallace, R. B. (1997). Change in social ties and subsequent mortality in rural elders. Epidemiology, 8, 475-48I. doi: |0.1097/0000 |648-199709000-0000 |

Cohen, S. (2004). Social relationships and health. American Psychologist, 59, 676-684. doi: 10.1037/0003-066X.59.8.676

Cruz, T. M., \& Obiena, A. (1991). Future directions for aging policy in Philippines. In: Population Aging in Asia. Asian Population Studies Series, 10(108 Bangkok Escap), 54-60.

Eboiyehi, F.A. (20|3). Our Lives are in Your Hands: Survival Strategies of Elderly Women Heads of Households in Rural Nigeria International Journal 
of Humanities and Social Sciences (IJHSS, USA) Vol. 3 No. 5. March.

Eboiyehi, F. A., \& Onwuzuruigbo, I. (2014). Care and Support for the aged among the Esan of SouthSouth Nigeria. The Nigerian Journal of Sociology and Anthropology (Special Edition on Ageing in Nigeria), I2(I).

Frank, J. B. (2002). The paradox of aging in place in assisted living. London: Bergin \& Garvey.

Ghana Statistical Service-GSS, Ghana Health ServiceGHS, \& ICF International. (2015). Ghana Demographic and Health Survey 2014. Rockville, Maryland, USA: GSS, GHS, and ICF International.

HelpAge International. (2008). Older people in Africa: A forgotten generation. In E. Stanley (Ed.), Leading global action on aging (pp. 1-8): HelpAge International.

Holt-Lunstad, J., Smith, T. B., \& Layton, J. B. (20/0). Social relationships and mortality risk: A metaanalytic review. PLoS Med, 7. doi: I0.137|/journal.pmed. 1000316

Institut National de la Statistique - INS/Niger and ICF International. 2013. Enquête Démographique et de Santé et à Indicateurs Multiples du Niger 2012. Calverton, Maryland, USA: INS/Niger and ICF International.

Institut National de la Statistique - INS/Côte d'Ivoire, \& ICF International. (20I2). Enquête Démographique et de Santé et à Indicateurs Multiples de Côte d'Ivoire 20I I-20I2. Calverton, Maryland, USA: INS/Côte d'lvoire and ICF International.

Institut National de la Statistique et de l'Analyse Économique-INSAE/Bénin, \& ICF International. (2013). Enquête Démographique et de Santé du Bénin 20II-2012. Calverton, Maryland, USA: INSAE and ICF International.

Kenyatta, J. (1938). Facing Mount Kenya. Secker and Warburg, London.

Ministère de la Planification, du Développement et de l'Aménagement du Territoire - MPDAT/Togo, Ministère de la Santé - MS/Togo, \& ICF International. (2015). Enquête Démographique et de Santé au Togo 2013-20I4. Rockville, Maryland, USA: MPDAT, MS and ICF International.
National Population Commission - NPC/Nigeria, \& ICF International. (20I4). Nigeria Demographic and Health Survey 2013. Abuja, Nigeria: NPC/Nigeria and ICF International.

National Research Council (U.S.), \& Committee on Population. (200I). Preparing for an ageing world: the case for cross-national research.

Ogwumike, F. O., \& Aboderin, I. (2005). Exploring the Links between Old Age and Poverty in Anglophone West Africa: Evidence from Nigeria and Ghana. British Society of Gerontology, 15(2), 7-I5.

Okumagba, P. O. (20II). Family Support for the Elderly in Delta State of Nigeria. Studies in Home and Community Science, 5(I), 2I-27.

Omowumi, B. E., Taiwo, P. A., \& Olaotan, S. Y. (2016). Old people's well-being in a total institution and the imperative of new policy directive. African Journal for the Psychological Study of Social Issues, 19(2), 12-27.

Noël-Miller, C. (2010). Spousal Loss, Children, and the Risk of Nursing Home Admission. Journals of Gerontology, Series B: Psychological Sciences and Social Sciences, 65(3), 370-380.

Riley, M. W. (1987). On the significance of age in sociology. American Sociological Review, 52(114).

Togonu-Bickersteth, F. (1997). Public alms solicitation among the Yoruba elderly in Nigeria lle - Ife. Department of Psychology. Obafemi Awolowo University. Ile-lfe.

Togonu-bickersteth, F., \& Akinyemi, A. I. (20/4). Ageing and national development in Nigeria: Costly assumptions and challenges for the future. African Population Studies, 27(2 Supp). https://doi.org//0.1 1564/27-2-48 I

United Nations. (2002). World population ageing, 1950 - 2050. United Nations, New York.

United Nations. (20I5). World Population Ageing 2015. New York.

United Nations Population Fund, \& HelpAge International. (20/5). Aging in the twenty-first century: a celebration and a challenge. United Nations Population Fund, New York and HelpAge International,

London. 